\title{
The market impact of futures trading by the National Pension Service (NPS) of Korea
}

\author{
Mincheol Woo \\ Special Investigation, Korea Exchange, Seoul, Republic of Korea, and \\ Meong Ae Kim \\ Glocal Campus, Konkuk University, Chungju-si, Republic of Korea
}

\section{Market impact of futures trading}

Received 9 February 2021 Revised 27 April 2021 30 May 2021 Accepted 30 May 2021

\begin{abstract}
The National Pension Service (NPS) of Korea is one of the largest institutional investors in the world and it has been known as the market stabilizer in the Korean stock market. Nevertheless, it is hard to find the research about the impact of the NPS on the futures market. We investigated the effect of the NPS's trading KOSPI200 futures on the returns, the liquidity and the volatility of the market using the recent ten years' transaction data. The main findings are as follows. First, the NPS's net investment flow (NIF) in the KOSPI200 futures market shows the predictability about the returns of both KOSPI200 futures and KOSPI200 spot index. Second, the NPS's NIF in the KOSPI200 futures market improves the liquidity of the KOSPI market, where the transactions involved in both the spot market and the futures market occur. Third, the NPS's NIF in the KOSPI200 futures market reduces the volatility of both the KOSPI200 futures market and the KOSPI market. Unlike the prior studies showing that our futures market tends to increase the volatility of the stock market through the volatility transfer, our finding suggests that the NPS's trading KOSPI200 futures contributes to decreasing the volatility in both markets. To the best of the authors' knowledge, this paper is the first study that investigates the impact of the NPS's trading KOSPI200 futures on the KOSPI200 futures market and the stock market. It shows that the NPS plays a role of the market stabilizer in the futures market. In addition, the NPS's trading KOSPI200 futures also affects the KOSPI stock market, stabilizing it in terms of both the liquidity and the volatility.
\end{abstract}

Keywords National Pension Service (NPS) of Korea, KOSPI200 futures, Net investment flow, Market stabilizer Paper type Research paper

\section{Introduction}

The National Pension Service (NPS) of Korea is the third largest institutional investor in the world and has the largest influence on the Korean stock market. The transactions by the NPS are known to increase the liquidity and reduce the volatility, which tends to stabilize the stock market. Like other institutional investors, the NPS also participates in the futures market for hedging or arbitrage transactions. However, it is hard to find the studies on the NPS's transactions in the futures market. We investigate the impact of the transactions by the NPS on the KOSPI200 futures market. Using the 10 years' transaction data during the period from January, 2010 to March, 2020, we investigate the effect of the NPS's transactions on the return, the liquidity and the volatility in both the futures market and the stock market.

Most prior studies on the NPS of Korea are limited to the spot market. In the spot market, the NPS pursues the negative feedback strategy, which is to buy stocks as the prices go up and to sell them as the prices go down. As the result, the NPS's transactions reduce the volatility, and the NPS plays a role as the market stabilizer. According to Gil et al. (2015), the

(C) Mincheol Woo and Meong Ae Kim. Published in Journal of Derivatives and Quantitative Studies: 선물연구. Published by Emerald Publishing Limited. This article is published under the Creative Commons Attribution (CC BY 4.0) licence. Anyone may reproduce, distribute, translate and create derivative works of this article (for both commercial and non-commercial purposes), subject to full attribution to the original publication and authors. The full terms of this licence maybe seen at http://creativecommons.org/licences/by/4.0/legalcode

JEL Classification - G12, G13, G23

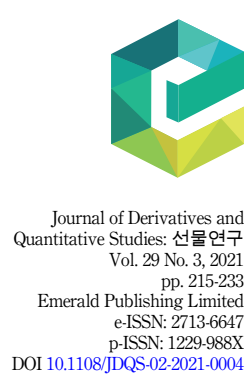



JDQS
29,3

NPS's transactions do not show the predictability about the market return or the individual stock returns in general. Woo and Kim (2019) suggests that the NPS is capable of forecasting the next day return in the KOSDAQ market. One of the previous studies suggests that the investment performance of the NPS is attributed to its stock selection ability and investment style (Woo and Yang, 2019).

Prior studies about the KOSPI200 futures market are as follows. The KOSPI200 futures leads the KOSPI200 spot index, which is the underlying asset of the futures instrument, and increases the volatility of the spot market transferring the volatility of the futures market (Bae et al., 2004; Kang et al., 2006; Ryoo and Smith, 2006). Institutional investors and foreign investors are considered to be superior in terms of information in the futures market as well as in the spot market. The NPS of Korea is also considered to participate in the derivatives market for hedging its spot position or for other transactions involved both in the spot market and the derivatives market. However, there are only few studies that deal with the NPS's transactions in the derivatives market due to the limited accessibility to the data.

In this paper, the NPS's transactions in the KOSPI200 futures market are identified from the data of the NPS's ownership in the disclosure system and the order document of the Korea Exchange. It is possible that our dataset might not include the NPS's entire transactions in the market. However, it is not likely that the transactions by other investors are included in our dataset. Main findings of this paper are as follows. First, the NPS's net investment shows the predictability about the returns of KOSPI200 futures and KOSPI200 spot index. Second, the NPS's net investment increases the liquidity in the KOSPI stock market, where the transactions involved in both the stock market and the futures market occur. Third, the NPS's net investment reduces the volatility in both the futures market and the stock market, which is different from the prior studies showing that the NPS's transactions in the futures market increase the volatility in the stock market through the volatility transfer.

Using the dataset identified from the transaction document of the Korea Exchange, this paper examines the impact of the NPS on the futures market and the stock market. Unlike the prior studies suggesting that the existence of the futures market exaggerates the volatility in the spot market, this paper shows that the NPS's net investment in the futures market reduces the volatility in the spot market. It suggests that the NPS plays a role as the market stabilizer as it does in the stock market. Further research about the NPS' transactions in the derivatives market is expected to understand the influence of the NPS on the KOSDAQ150 futures market, KOSPI200 mini futures market and KOSPI200 options market.

The remaining parts are as follows. In part 2, prior studies about the NPS's influence in the Korean stock market and the KOSPI200 futures market are documented. In part 3, the process of identifying the NPS's transactions and the research methodology are explained. In part 4, empirical findings are shown, and in part 5, the summary and the implication are presented.

\section{Prior studies}

\subsection{Influence of the National Pension fund of Korea in the Korean stock market}

Most prior studies dealing with the NPS focus on the spot market and it is hard to find the study of the NPS's transactions in the derivatives market. In the previous studies, the NPS's influence in the Korean stock market can be summarized as shown in Table 1.

First, in the spot market, the NPS pursued the negative feedback strategy, which is to buy the stocks as the prices go down and to sell the stocks as the prices go up. This is also found in the separate studies of the KOSPI market and the KOSDAQ market (Kho et al., 2008; Woo and Kim, 2018, 2019). Second, the effect of the NPS's transactions is minimal on both the price of the KOSPI index and the price of individual stocks in the KOSPI market. The NPS reduces the volatility at both the market level and the individual stock level, playing as a role of the 


\begin{tabular}{|c|c|}
\hline Authors & Empirical findings \\
\hline Kho et al. (2008) & $\begin{array}{l}\text { They did not find the evidence that the NPS's transactions distorted the stock market. As } \\
\text { it pursued the negative feedback strategy, the NPS did not accelerate the price rise or } \\
\text { decline. The evidence of increasing the volatility was not found either }\end{array}$ \\
\hline Nam et al. (2008) & $\begin{array}{l}\text { The NPS did not increase the volatility but stabilized the market. Its role as the market } \\
\text { stabilizer was obvious during the period of the bearish market, when the NPS reduced its } \\
\text { selling amount }\end{array}$ \\
\hline Gil et al. (2015) & $\begin{array}{l}\text { After investigating the NPS's investment performance and ability of market timing, the } \\
\text { authors did not find the evidence that the NPS had the predictability about the returns of } \\
\text { both the market and the individual stocks }\end{array}$ \\
\hline Yim (2013) & $\begin{array}{l}\text { More than } 99 \% \text { of the changes in the KOSPI index are explained by the change of the } \\
\text { index itself, and the changes explained by the NPS's fund are very small. A total of } 97 \% \\
\text { of the changes in the NPS's investment returns is explained by the change of the NPS's } \\
\text { fund itself, and the part explained by the KOISPI index is less than } 3 \%\end{array}$ \\
\hline $\begin{array}{l}\text { Woo and Kim } \\
(2018)\end{array}$ & $\begin{array}{l}\text { The NPS pursues the negative feedback strategy in the KOSPI market. As the NPS's net } \\
\text { investment increases, the volatility decreases. Investment trust companies and other } \\
\text { financial companies follow the NPS's transactions }\end{array}$ \\
\hline $\begin{array}{l}\text { Woo and Kim } \\
\text { (2019) }\end{array}$ & $\begin{array}{l}\text { The NPS showed the negative feedback trading in the KOSDAQ market. The buying of } \\
\text { the NPS is positively related to the next day return, increases the liquidity and reduces } \\
\text { the volatility in the KOSDAQ market. }\end{array}$ \\
\hline $\begin{array}{l}\text { Woo and Yang } \\
\text { (2019) }\end{array}$ & $\begin{array}{l}\text { The monthly rate of return in the NPS's domestic portfolio is } 0.57 \% \text { in average. The } \\
\text { decomposition of the NPS's investment performance shows that the investment return of } \\
\text { the NPS comes mainly from its stock selection ability and investment style }\end{array}$ \\
\hline
\end{tabular}

\section{Market impact of futures trading}

Table 1 .

Literature about the NPS's influence in the Korean stock market

market stabilizer (Kho et al., 2008; Nam et al., 2008; Yim, 2013). Third, there are conflicting results about the NPS's return predictability. According to Gil et al. (2015), the NPS' investment shows no predictability about the returns in the stock market. Woo and Kim (2019) show that the NPS's investment in the KOSDAQ market is positively related to the next day return due to the herding behavior by other investors. Lastly, Woo and Yang (2019), decomposing the NPS's investment performance into the stock selection, the market timing and the investment style as in Daniel et al. (1997), show that the investment performance of the NPS comes mainly from its stock selection ability and investment style.

\subsection{KOSPI200 futures market}

The literature of the KOSPI200 futures market is summarized in Table 2. First, there is the return spillover, which means that the price changes in the futures market occur earlier than in the spot market. As new information arrives, it takes longer for the prices to change in the spot market, where there are many stocks to be affected than in the KOSPI200 futures market, where there is only one product (Kang et al., 2006; Min and Najand, 1999). Second, the volatility in the futures market amplifies the volatility in the spot market through the volatility spillover (Kang et al., 2006; Ryoo and Smith, 2006; Min and Najand, 1999; Bae et al., 2004). Third, among the investors that participate in the futures market, the institutional investors are the most informed (Ryu, 2013; Kang and Ryu, 2014), while the foreign investors are the most informed according to Ko (2012). Lee (2013) showed that the transactions by the high-frequency traders do not make a contribution to the liquidity and the price discovery. Lastly, Kang and Ryu (2014) showed that the hypothesis of stealth trading by the mid-sized traders is not supported in the futures market since they do not have information power in the market (see Table 2). 


\section{JDQS 29,3}

\section{8}

Authors Empirical findings

Kang et al. (2006)

Ryoo and Smith (2006)

Ryu (2013)

Min and Najand (1999)

Lee (2013)

Ko (2012)

Kang and Ryu (2014)

Table 2.

Literature about the KOSPI200 futures market

Bae et al. (2004)
KOSPI200 futures and options market lead the changes in the returns and the volatility in the spot market. The relation of lead and follow seems to be caused by the difference in the transaction costs of the three markets

Futures contracts accelerate the speed by which the information is reflected in the spot price, reduce the sustainability of the information and increase the volatility in the spot market. It is obvious that the futures market leads the spot market, although the evidence of the opposite direction is weak

The price effect reflected in the futures contract is permanent and the price discovery effect is larger in the futures market than in the options market. Futures transactions by the institutional investors show more information than those by the individual investors. The futures market leads the options market

The futures market leads the spot market like the results in the US and other countries. The trading volume in the futures market significantly affects the changes in the volatility in both the futures market and the spot market

The transactions by the high-frequency traders neither provide the liquidity in the futures market nor make a contribution to enhancing the market quality. The transactions rather impedes the price discovery and are not profitable when the trading costs are considered

Among the investor groups of foreign investors, institutional investors, individual investors and other types of corporations, foreign investors are more informed than domestic investors, in particular, individual investors

The stealth trading hypothesis is not supported because the medium size transactions are not lot more informative than those of other sizes. Foreign investors are more informed than individual investors and institutional investors are more informed than other types of investors. Individual investors are not homogenous

volatility in the spot market at the same time. The volatility transfer from the futures market to the spot market is observed

\section{Data and methodology}

\subsection{Data}

In this paper, the NPS's orders for derivatives contracts are identified based on the stock account data used in Woo and $\operatorname{Kim}(2018,2019)$ and Woo and Yang (2019). The collecting process of the stock accounts is as follows. First, we looked for the cases that have the NPS as the reporting entity in the disclosed documents of the report of large ownership excluding $5 \%$ of the entire shares and/or the report of the shares owned by board members or large shareholders with more than $10 \%$ of the entire shares. Second, we sorted the transactions involved with the NPS by the date, the asset, the price and the amount. Third, using the order document in the Korea Exchange, we selected the accounts that show the match to the NPS's transactions in the list described above. We added the transactions of two or more accounts to find the corresponding account to the disclosed information if no exact match appears in the previous step. Through this process, 3,920 accounts for the NPS are identified. Then the derivatives orders were sorted out based on the securities firms' account number structure, which is unique to each firm and is transformed when the orders are submitted to the Korea Exchange. Finally, the trading orders from 785 accounts of 35 securities firms are identified. In this study, we consider that all of the derivatives trading orders given by those accounts are for the NPS.

\subsection{Methodology}

This study investigates the NPS's net investment flow in the first nearest month contracts of KOSPI200 futures for about the 10-year period from January, 2010 to March, 2020. The net 
investment flow (NIF) in Kamesaka et al. (2003) and Schwarz (2012) are used to measure the investment direction of the NPS. NIF $t$ is calculated by dividing the difference between the amount bought and the amount sold with the sum of them on day $t$ as in equation (1). This measure is also used in Kho et al. (2008) and Woo and Kim (2015). We use the trading amount instead of the trading volume in order to control the effect of the event at March, 27, 2017, when the multiplier of KOSPI200 futures changed from 500,000 won to 250,000.

$$
N I F_{t}=\frac{\text { BuyWon }_{t}-\text { SellWon }_{t}}{\text { BuyWon }_{t}+\text { SellWon }_{t}}
$$

where,

BuyWont: Amount of KOSPI200 futures contracts purchased by the NPS on day $t$,

SellWon: Amount of KOSPI200 futures contracts sold by the NPS on day $t$.

We investigated the impact of the NPS's investment in KOSPI200 futures on the returns, the liquidity and the volatility in the market, using the regression models shown below. We also investigate whether the NPS's investment in KOSPI200 futures affect the spot market as well since the two markets are connected to each other. In all equations, $N I F_{[t-T, t-1]}$ is the net investment flow (NIF) by the NPS for the period from day $t-T$ to day $t-1$. In equation (2) and equation (3), the dependent variables are the return of KOSPI200 futures on day $t$ and the basis in the market, respectively. We also carried out the regression analyses on the return of KOSPI200 spot index on day $t$. In equation (4), the dependent variable is the trading amount of KOSPI200 futures on day $t$, which represents the liquidity. Estimation using equation (4) is carried out for the stock markets as well, which are the KOSPI market and the KOSDAQ market. The dependent variables for the regressions are the trading amount on day $t$ in each market. We also estimated the effect of the NPS's NIF on the liquidity using the Amihud measure. In equation (5), the dependent variable is the volatility on day $t$, which is calculated from dividing the difference between the highest price and the lowest price during the day with the average of the two prices. Equation (2)-(5) include the control variables which might affect the dependent variable. FutCAR $[t-T, t-1]$ is the cumulative abnormal return of KOSPI200 futures for the period from day $t-T$ to day $t-1$. The abnormal return is calculated by subtracting the return of KOSPI from the return of KOSPI200 futures. FutVol $l_{[-T, t-1]}$ is the average daily volatility for the period from day $t-T$ to $t-1$. FutWon $[t-T, t-1]$ is the average daily trading amount of KOSPI200 futures for the period from day $t-T$ to day $t-1$. Basis $s_{[t-T, t-1]}$ is the average daily basis for the period from day $t-T$ to $t-1$.

$$
\begin{aligned}
\text { FutRet }_{t}= & \alpha_{0}+\beta_{1} \times \operatorname{NIF}_{[t-T, t-1]}+\beta_{2} \times \operatorname{FutCAR}_{[t-T, t-1]}+\beta_{3} \times \text { FutVol }_{[t-T, t-1]} \\
& +\beta_{4} \times \operatorname{StkWon}_{[t-T, t-1]}+\beta_{5} \times \text { FutWon }_{[t-T, t-1]}+\varepsilon_{t} \\
\text { Basis }_{t}= & \alpha_{0}+\beta_{1} \times \operatorname{NIF}_{[t-T, t-1]}+\beta_{2} \times \operatorname{Basis}_{[t-T, t-1]}+\beta_{3} \times \text { FutVol }_{[t-T, t-1]} \\
& +\beta_{4} \times \operatorname{StkWon}_{[t-T, t-1]}+\beta_{5} \times \operatorname{FutWon}_{[t-T, t-1]}+\epsilon_{t} \\
\text { FutWon }_{t}= & \alpha_{0}+\beta_{1} \times \operatorname{NIF}_{[t-T, t-1]}+\beta_{2} \times \operatorname{FutCAR}_{[t-T, t-1]}+\beta_{3} \times \text { FutVol }_{[t-T, t-1]} \\
& +\beta_{4} \times \operatorname{StkWon}_{[t-T, t-1]}+\beta_{5} \times \text { FutWon }_{[t-T, t-1]}+\varepsilon_{t} \\
\text { Volatility }_{t}= & \alpha_{0}+\beta_{1} \times \operatorname{NIF}_{[t-T, t-1]}+\beta_{2} \times \text { FutCAR }_{[t-T, t-1]}+\beta_{3} \times \text { FutVol }_{[t-T, t-1]} \\
& +\beta_{4} \times \operatorname{StkWon}_{[t-T, t-1]}+\beta_{5} \times \text { FutWon }_{[t-T, t-1]}+\varepsilon_{t}
\end{aligned}
$$

Market impact of futures trading 
JDQS 29,3

220

where,

$N I F_{[t-T, t-1]}:\left(\right.$ Buy Won $_{[t-T, t-1]}-$ SellWon $\left._{[t-T, t-1]}\right) /\left(\right.$ BuyWon $_{[t-T, t-1]}+$ SellWon $\left._{[t-T, t-1]}\right)$,

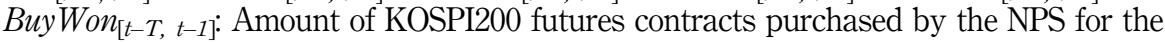
period from day $t-T$ to day $t-1$,

SellWon $[t-T, t-1]$ : Amount of KOSPI200 futures contracts sold by the NPS for the period from day $t-T$ to day $t-1$,

FutRet $t_{t}$ Return of KOSPI200 futures on day $t$,

Basis $_{t}$ : Price of the KOSPI200 futures minus the price of the KOSPI200 on day $t$,

StkWon $n_{[t-T, t-1]}$ is the average trading amount in the stockmarket for the period from day $t-T$ to day $t-1$.

FutWon: Trading amount in the KOSPI200 futures market on day $t$,

Volatility: (Highest price - lowest price) $/\{($ Highest price + Lowest price $) / 2\}$ on day $t$.

\section{Empirical results}

Table 3 shows the correlation between the variables included in the regression models. It shows the connection between the futures market and the spot market, which is consistent with the results from the previous studies. It also shows that the NPS's NIF in KOSPI200 futures is closely related to the basis between the futures price and the spot price, the return of the KOSPI200 and the return of the KOSPI200 futures. Both the futures return and the spot return of KOSPI200 show the significantly positive correlation only with the NIF for the past 15-day period. The basis shows the statistically significant and negative correlation with the NIF in KOSPI200 futures. The statistically significant and positive correlation between FutCARs and FutRet suggests that there is autocorrelation in the returns of KOSPI200 futures. The NPS' NIFs in KOSPI200 futures and FutCARs generally show the statistically significant and negative relation for the same windows of the past period. For example, the correlation -0.0419 between FutCAR $[t-T, t-1]$ and $N I F_{[t-3, t-1]}$ suggests that during the corresponding period, the NPS shows the net buying in the market when the past cumulative abnormal returns of KOSPI200 futures decreases, while it shows the net selling in the market when the past cumulative abnormal returns of KOSPI200 futures increases.

Table 4 shows the effect of the NPS's NIF in KOSPI200 futures on the returns in the KOSPI200 futures and the KOSPI market. Panel A shows the result of regressing the current return of KOSPI200 futures on the NPS' NIF in the past. FutCAR $R_{[t-T, t-1]}$ is a variable that controls the effect of the past cumulative abnormal return of KOSPI200 futures. The return of KOSPI200 futures increases as the NPS's NIFs for the past 5-day period through the past 30day period increase. The relation is significantly significant. It is consistent with the result of Kang et al. (2006) and that of Min and Najand (1999). This result is meaningful since it is estimated from the regression model in which the effect of the past cumulative abnormal return is controlled. It can also be interpreted that the NPS's investment in KOSPI200 futures shows the predictability on the return in the market. This is different from the result of Gil et al. (2015), according to which the NPS' investment does not have the prediction power about the prices in the Korean stock market.

Panel B shows the result of regressing the current basis between the futures price and the spot price of KOSPI200 on the NPS' NIF in KOSPI200 futures. The current basis shows the statistically significant and negative relation to the NPS's past NIF in KOSPI200 futures. The relation held when the absolute value of the basis is used as the dependent variable, though the result is not reported. Panel $\mathrm{C}$ shows the result of regressing the current return of the KOSPI200 spot index on the NPS's past NIF in KOSPI200 futures. The regression coefficient of the NPS' NIF is statistically and significantly positive, which is consistent with the relation in the correlation table. The futures return is marginally significant, but the spot return is not statistically significant only in the result from the regression with the past 30-days data. 


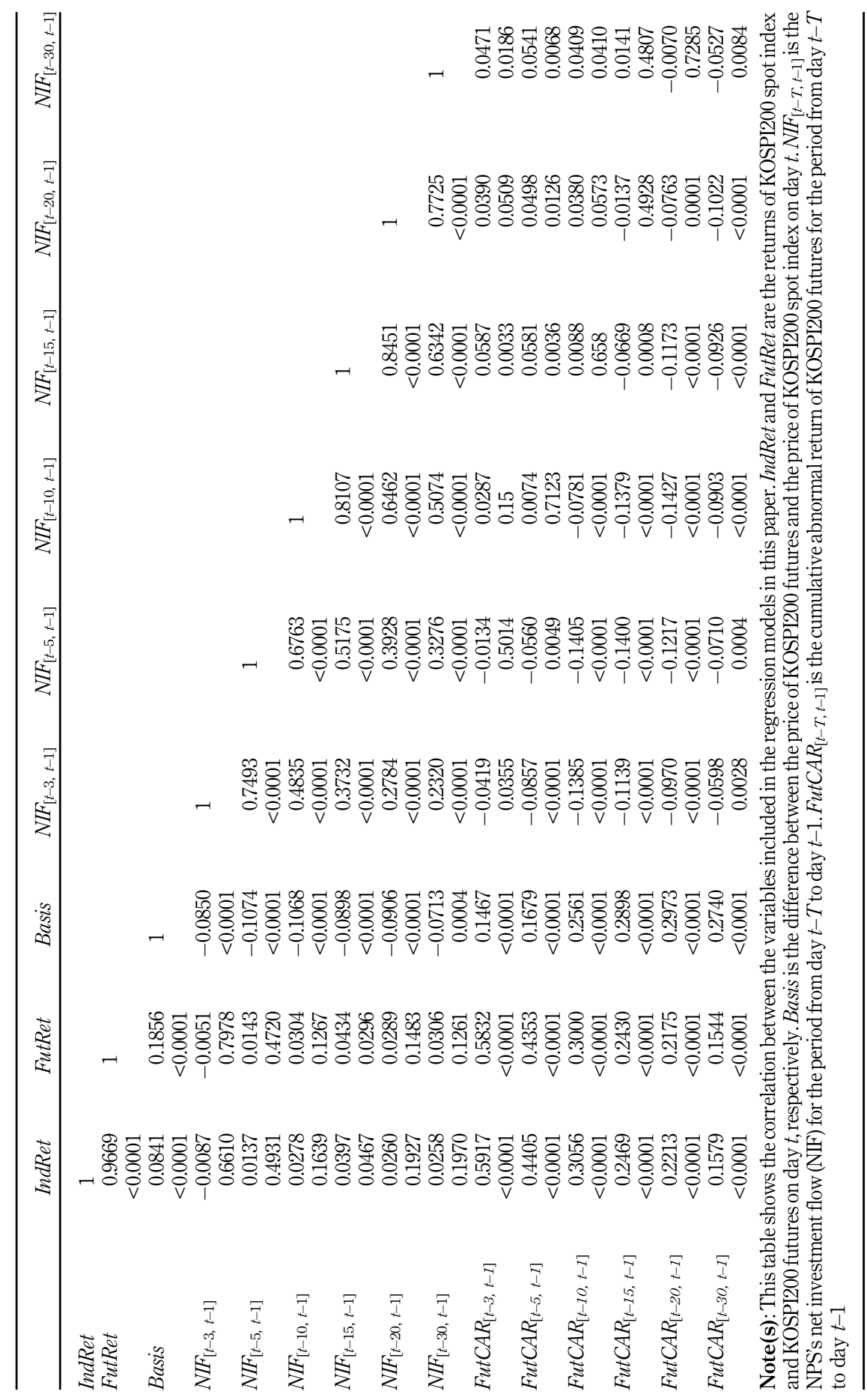

Market impact of futures trading

221

Table 3.

Correlation 
JDQS

29,3

222

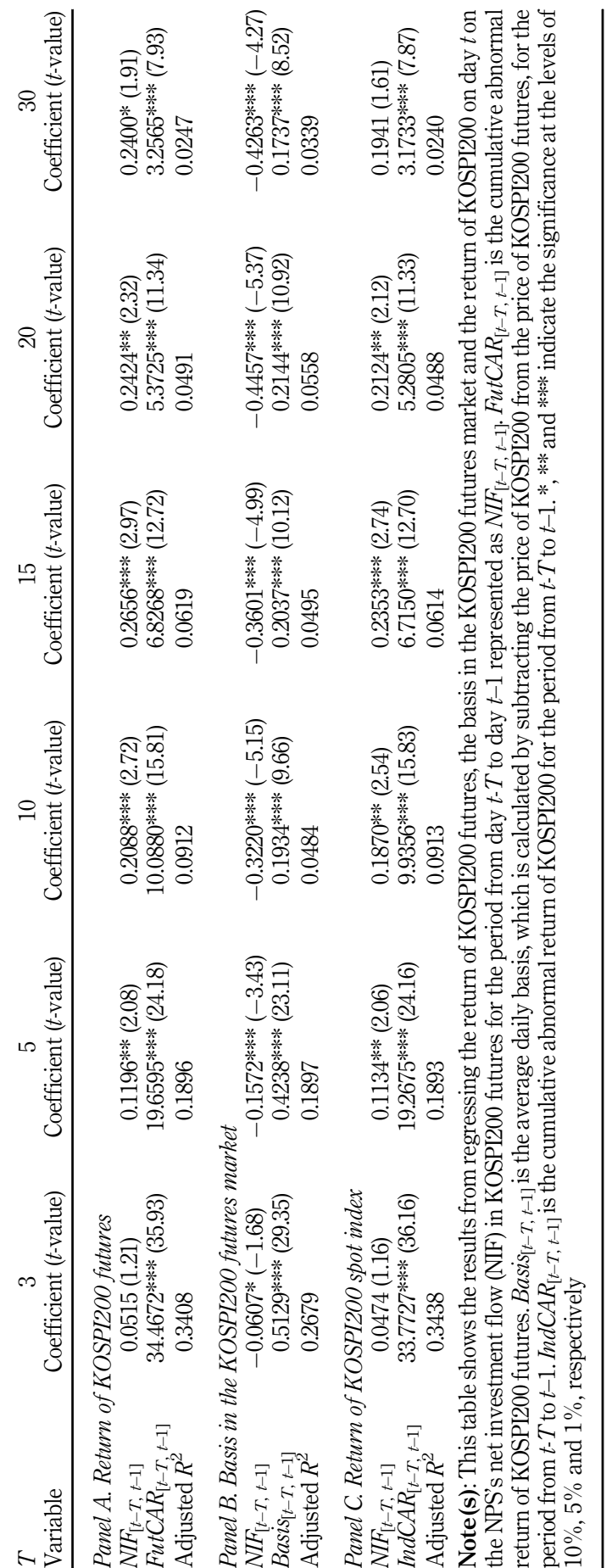

Table 4.

The effect of the NPS's NIF on the returns (I) 


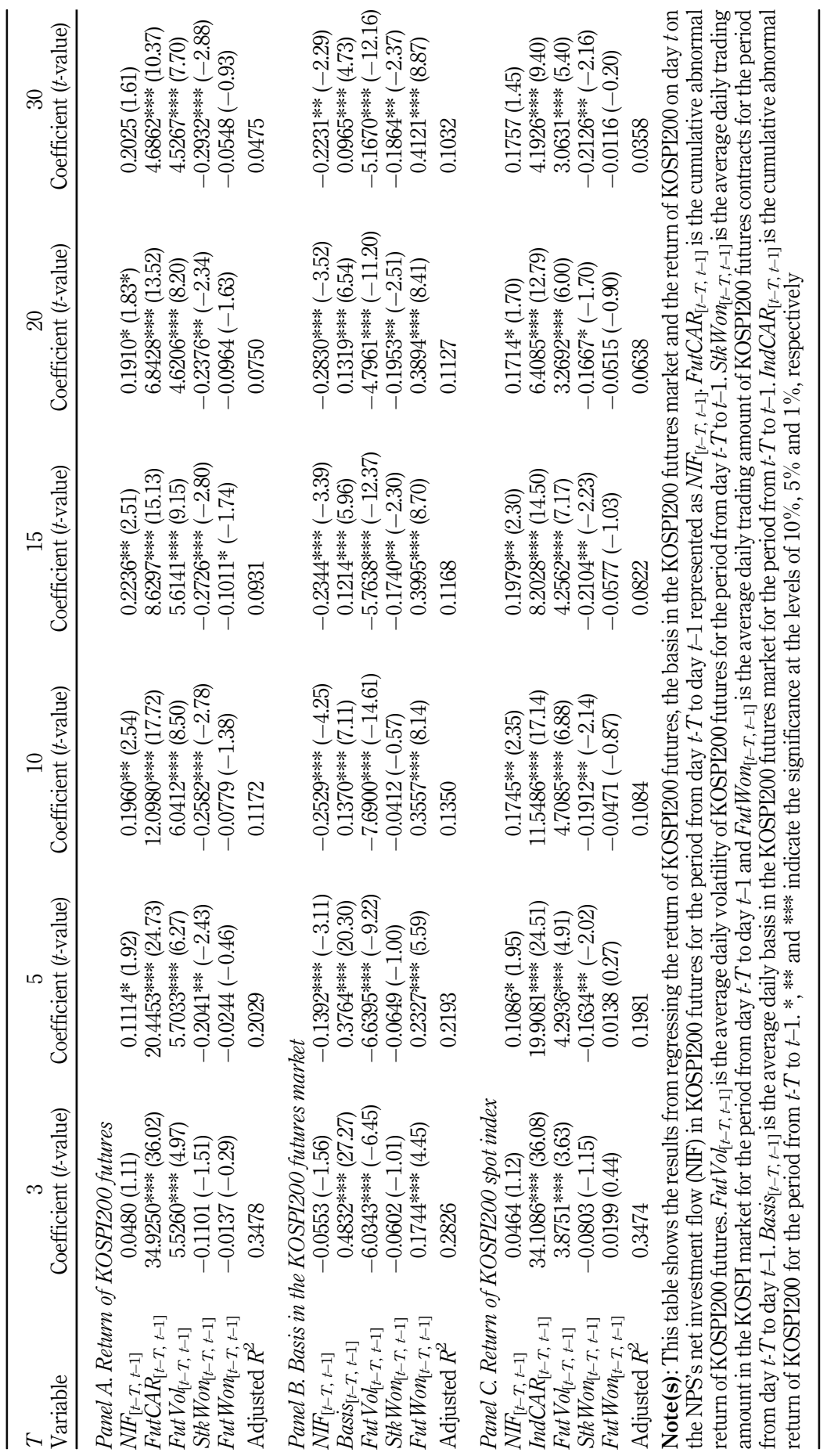

Market impact of futures trading

223

Table 5.

The effect of the NPS's NIF on the returns (II) 
JDQS 29,3

Table 5 shows the result from the regression models that include the variables representing the volatility and the liquidity, which are known to affect the returns. The control variables are calculated for the same period as that used to calculate the NPS's NIF in KOSPI200 futures.

According to panel A, the return of the KOSPI200 futures increases as the NPS's NIF in the futures market increases. The regression coefficients are statistically significant except for the NIF for the past 30 days. The result shows that the NPS's past investment has the prediction power about the current return in the KOSPI200 futures market, which is different from the results about the stock market in the prior studies. Panel B presents the effect of the NPS' NIF in KOSPI200 futures on the basis in the market. The result shows that the basis between the futures price and the spot price of the KOSPI200 decreases as the NPS's NIF increases. The regression coefficients are statistically significant for most windows of the NIFs. The result is consistent with that in Table 4 except for the NIF of past 3-day period, which does not show the statistically insignificant coefficient. Panel C shows the effect of the NPS's NIF on the return of KOSPI200 using the regression models that include control variables. The NPS's NIF in the futures market positively affects the return of the KOSPI200 spot index and the coefficients are statistically significant in most windows of the past NIF. The results in Table 5 suggest that the NPS's NIF in the futures market affects the returns of both futures return and the spot index return. Its negative effect on the basis suggests that the NPS's NIF in KOSPI200 futures affects the spot price more than the futures price. This result is consistent with Kang et al. (2006) and Ryoo and Smith (2006), which shows that the KOSPI200 futures market leads the spot market in terms of the direction regarding the return and the volatility.

Table 6 is the result of regressing the liquidity on the NPS's NIF in KOSPI200 futures. Woo and Kim (2019) shows that the NPS's transaction enhances the liquidity in the KOSDAQ market. But it is hard to find a previous research that specifically deals with the relation between the NPS's transactions in the futures market and the liquidity. Panel A shows that the increases of the NPS's NIF in the past period contributes to the enhancement of the liquidity, which is measured as the trading amount on day $t$. The NIF for the past 15 days, in particular, shows the largest contribution to the liquidity of the KOSPI200 futures market. Panel B is the result from analyzing the effect of the NPS's NIF in KOSPI200 futures on the liquidity of the entire stock market consisting of the KOSPI market and the KOSDAQ market. It shows that the stock liquidity is positively related to the NPS' NIF increases when the cumulative abnormal return of KOSPI200 futures is controlled for. The regression coefficients of the NIFs are statistically significant in the cases of the past 3-days, 5-days and 10-day periods. Panel $\mathrm{C}$ is the result of analyzing the effect of the NPS's NIF on the liquidity of the KOSPI market, where the transactions involved in both the futures market and the stock market at the same time are more likely to occur than in the KOSDAQ market. The result shows that the liquidity of the KOSPI market is positively related to the NPS's NIF for the several past periods, and all of the regression coefficients are statistically significant. Panel D is the result of analyzing the effect of the NPS's NIF on the liquidity of the KOSDAQ market. The result shows that the relation between the two variables is not statistically significant in most cases, which is as expected. Only the effect of the NIF for the past three days is significantly positive at the confidence level of $10 \%$. Table 5 shows that the NPS's NIF in KOSPI200 futures contributes to enhancing the liquidity of the futures market as well as that of the stock market. However, it needs to be estimated whether the relation remains the same when other variables that may affect the liquidity are controlled for.

Table 7 shows whether the effect of the NPS's NIF on the current liquidity is still statistically significant when the past volatility of the futures market and the past liquidity of both the futures market and the stock market are controlled for. Panel A shows that the regression coefficients of the NPS's NIF are positive for most windows but not statistically significant. The regression coefficient of the NIF for the last 30 days even shows the 


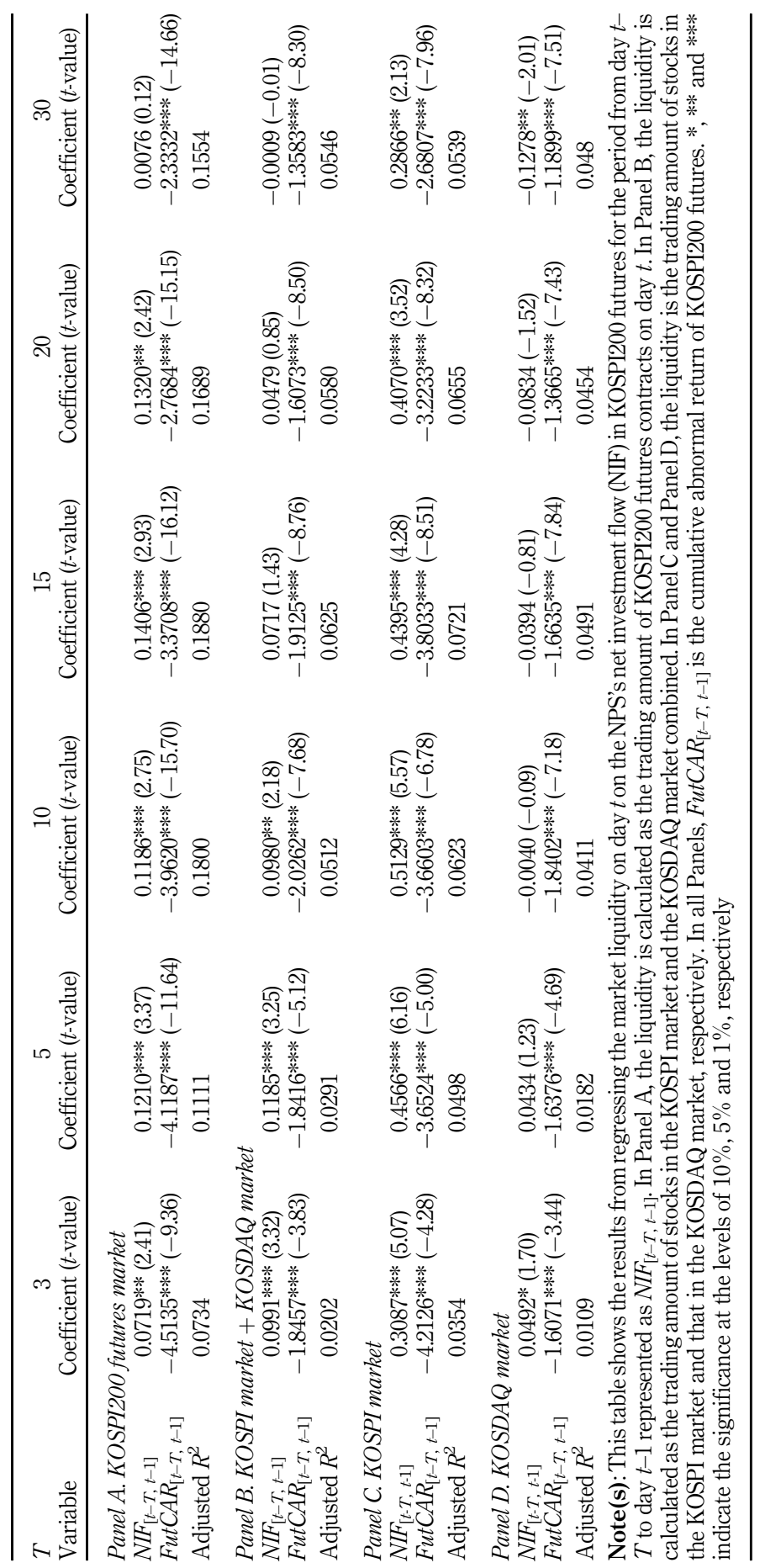

Market impact of futures trading

225

Table 6.

The effect of the NPS's NIF on the liquidity (I) 


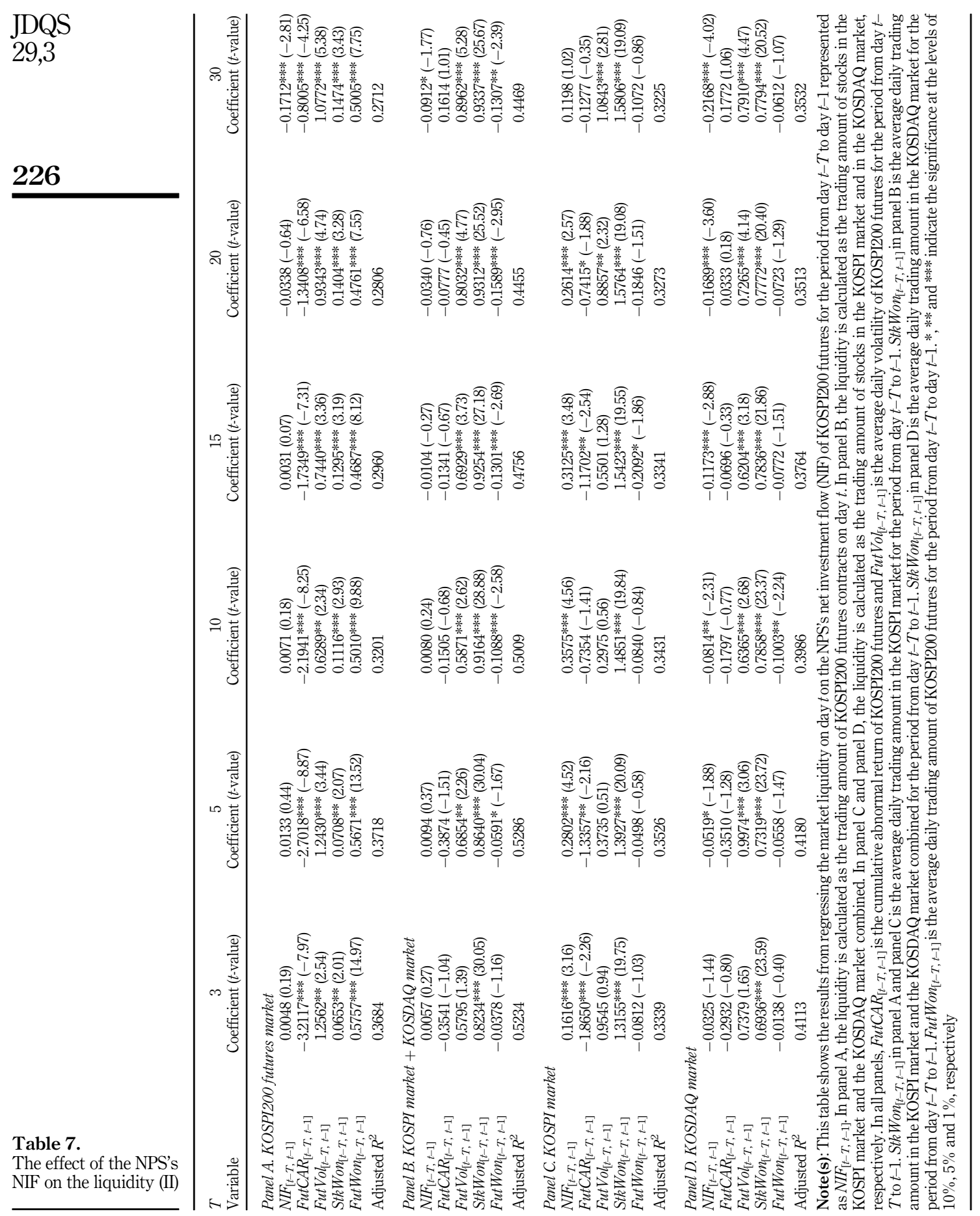


statistically negative sign. Panel $\mathrm{B}$ shows the result of regressing the current liquidity of the entire stock market consisting of the KOSPI market and the KOSDAQ market on the NPS's NIF. Unlike the result of Table 6, the effect of the NPS's NIF on the liquidity disappears when it is estimated using the regression models with control variables that may affect the liquidity. In the case of the NIF for the period of longer than 15 days, the signs of the regression coefficient changed to minus, and the coefficient of the NIF for the past 30 days is even statistically significant and negative. Panel $\mathrm{C}$ shows the result from the regression in the KOSPI market. The effect of the NPS's NIF is statistically significant and positive on the liquidity when it is estimated with the regression model with the control variables that may affect the liquidity. It suggests the contribution of the NPS's transactions to the liquidity, which has not been reported in the previous studies. Panel D shows the result of the regression analysis for the KOSDAQ market. In Table 6, the NPS's NIF for the past three days showed the marginally significant and positive effect on the liquidity. Unlike the result in Table 6, panel D shows the NPS' NIF in KOSPI200 futures reduces the liquidity in the KOSDAQ market when the relation is estimated with the regression models that include control variables. The result in Table 7 suggests that the NPS's NIF in KOSPI200 futures increases the liquidity of the KOSPI market and decreases the liquidity of the KOSDAQ market. It adds findings to the literature about the NPS's impact on the market. Woo and Kim (2019) shows that the NPS's transactions in the KOSDAQ market enhances the liquidity and reduces the volatility of the market. Prior studies including Kho et al. (2008) and Gil et al. (2015) show that the NPS' investment has no impact on the liquidity and the volatility of the market. The result in Table 7, which shows the positive relationship between the NPS's NIF in KOSPI200 futures and the liquidity of the KOSPI market, implies that the transactions by the NPS in the KOSPI200 futures market may be related to its arbitrage transactions.

Table 8 shows the result of the robustness test using the Amihud measure as the measure of the liquidity [1]. The Amihud measure is also called the illiquidity measure since the higher value of the measure means the lower liquidity (Amihud, 2002). We multiply $10^{9}$ by the calculated value of the measure as in Kang and Jeong (2018) since the regression coefficient becomes very small if the original value is used in the regression.

Panel A shows that the regression coefficient of the NPS's NIF has the positive sign, but it is not statistically significant. Only the NIF for the past 30 days has the statistically significant and negative effect on the Amihud measure, suggesting the NIF is positively related to the liquidity level of the market, which is different from the result of Table 7. Panel $B$ shows the result of regressing the liquidity of the stock market on the NPS's NIF in the KOSPI200 futures. The regression coefficient has the positive sign but is not statistically significant. Panel $\mathrm{C}$ and panel $\mathrm{D}$ show the results of regressing the liquidity of the KOSPI market and the liquidity of the KOSDAQ market, respectively. Since the Amihud measure is an illiquidity measure, the result in panel $\mathrm{C}$ suggests that the increase of the NPS's NIF in KOSPI200 futures enhances the liquidity of the KOSPI market, which is consistent with the results from Table 7. In panel D, the effect of the NPS's NIF on the liquidity of the KOSDAQ market is not statistically significant. The results of Table 8 suggest that the impact of the NPS's NIF on the liquidity of the KOSPI market does not change when the Amihud measure is used in the regression model.

Table 9 shows the result of regressing the volatility on the NPS's NIF in the KOSPI200 futures. According to previous studies, the futures market increases the volatility of the spot market, transferring the volatility (Kang et al., 2006; Ryoo and Smith, 2006; Min and Najand, 1999; Bae et al., 2004). Unlike the results from the previous studies, panel A and panel B of Table 9 shows that the NPS's NIF in the KOSPI200 futures market is negatively related to the volatility of the market, and the regression coefficients are statistically significant. It also reduces the volatility of the KOSPI market, where the transactions involved both in the spot market and the futures market are likely to occur. The result can be explained by the result of 


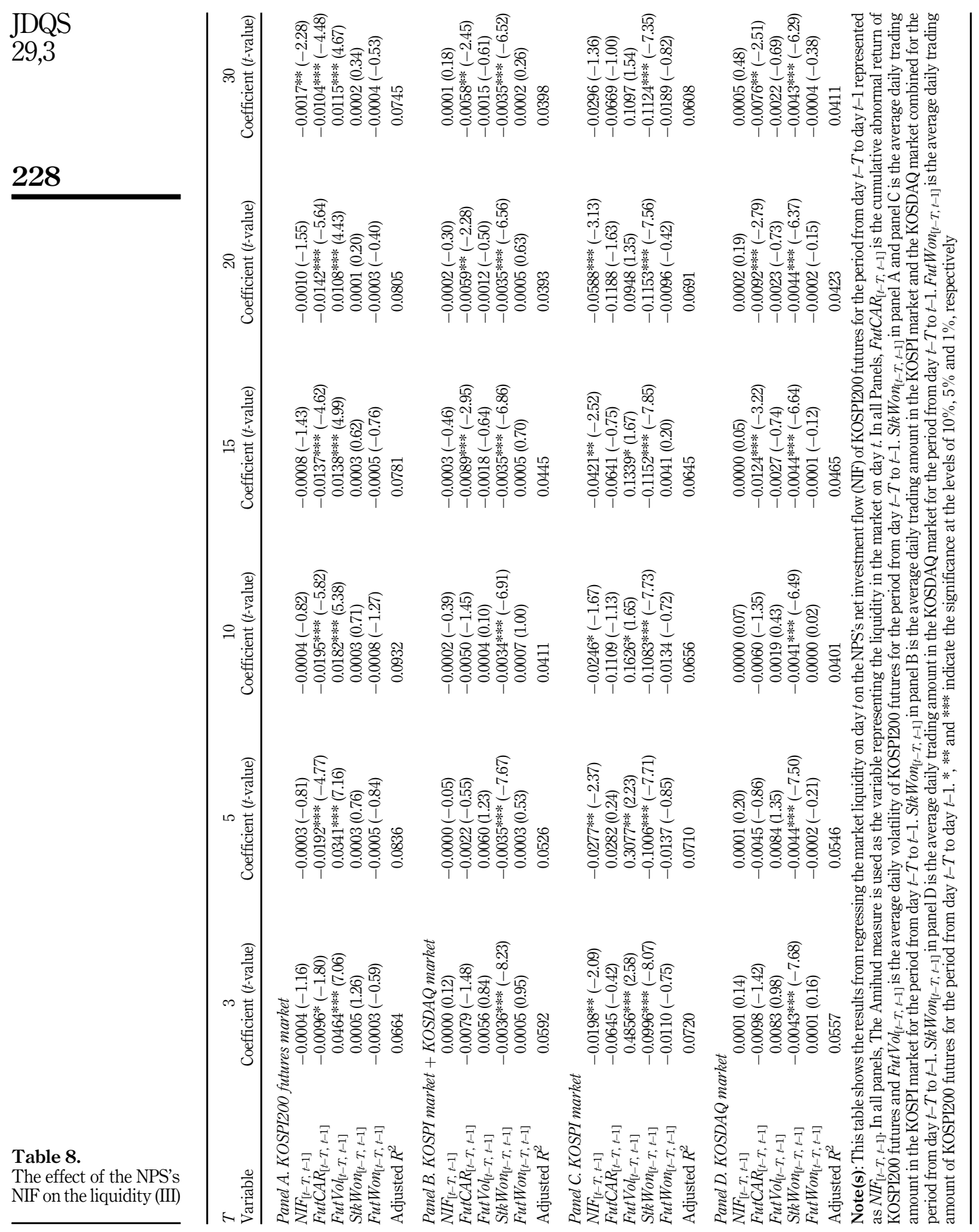




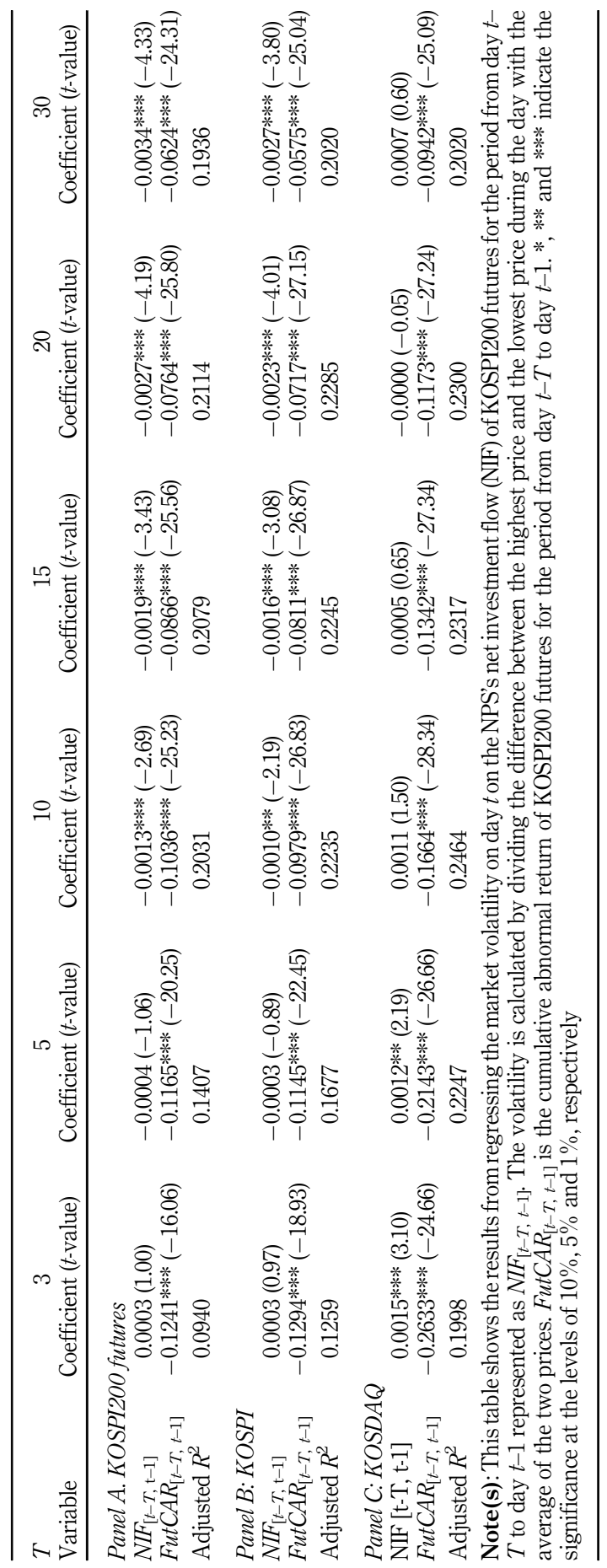

Market impact of futures trading

229

Table 9.

The effect of the NPS's NIF on the volatility (I) 
JDQS 29,3

Kim and Woo (2021), which shows that the NPS's NIFs in the KOSPI200 futures market is negatively related to the past returns of KOSPI200 futures. Panel C shows that the NPS's NIFs in the KOSPI200 futures market for the past 3-days and 5-day periods increase the volatility of the KODAQ market. However, the relation between the NPS's NIF and the volatility in Table 9 has the limitation since it is from the regression model that does not control for the effect of other variables.

Table 10 shows the effect of the NPS's NIF in the KOSPI200 futures on the volatility when other variables that may affect the volatility is controlled for. In panel A, the volatility of the KOISPI200 futures market decreases as the increase of the NPS's NIF in the past periods except for the 3 -day period. The regression coefficients are statistically significant. The magnitude of the coefficient becomes larger as the corresponding past period is longer. Panel B shows that the volatility of the KOSPI market also decreases as the NPS's NIF in the futures market increases. Like the result from panel A, the volatility decreases more as the corresponding past period is longer. Panel C shows that the effect of the NPS's NIF in the KOSPI200 futures market on the volatility of the KOSDAQ market. The regression coefficients are not statistically significant for most periods except for the past 3-day period.

According to Nam et al. (2008) and Woo and Kim (2018), the NPS reduces the volatility of the stock market since it pursues the negative feedback strategy in the market. The NPS's NIF is negatively related to the past returns of the KOSPI200 futures in Kim and Woo (2021). The results from previous studies suggest that the NPS's investment reduces the volatility in the KOSPI market and the KOSPI200 futures market. However, when the relation is estimated with the model that includes control variables, the NPS's NIF does not show a statistically significant effect on the KOSDAQ market unlike the result from Table 9.

\section{Summary and implication}

The National Pension Service of Korea (NPS) contributes to stabilizing the market as the institutional investor with the largest influence in the Korean stock market. The NPS is considered to trade financial derivatives for hedging or other transactions involved in both the stock market and the futures market, but it is hard to find academic research about the NPS's transactions in the derivatives market.

This paper analyzed the impact of the NPS's trading KOSPI200 futures on the futures market and the stock market using the NPS's account data identified from the disclosed reports of the large shareholder's ownership and the order document of the Korea Exchange. Main findings of this paper are as follows. First, the NPS's net investment flow in the KOSPI200 futures market shows the return predictability about both KOSPI200 futures and KOSPI200 spot index. Second, the NPS's net investment flow in the KOSPI200 futures market enhances the liquidity of the KOSPI market, where the transactions involved in both the stock market and the futures market occur. Third, the NPS' net investment flow in the KOSPI200 futures market reduces the volatility of both the KOSPI200 futures market and the KOSPI stock market. The findings of this paper suggest that the NPS's trading in the futures market contributes to the market stabilization by reducing the volatility. It is different from the results of the previous studies, which showed that the futures market exaggerates the volatility by transferring it to the stock market. Further studies are expected about the impact of the NPS's trading financial derivatives on the transfer of information, liquidity or volatility between the markets. Other institutional investors' trading in the KOSPI200 futures market may be different 


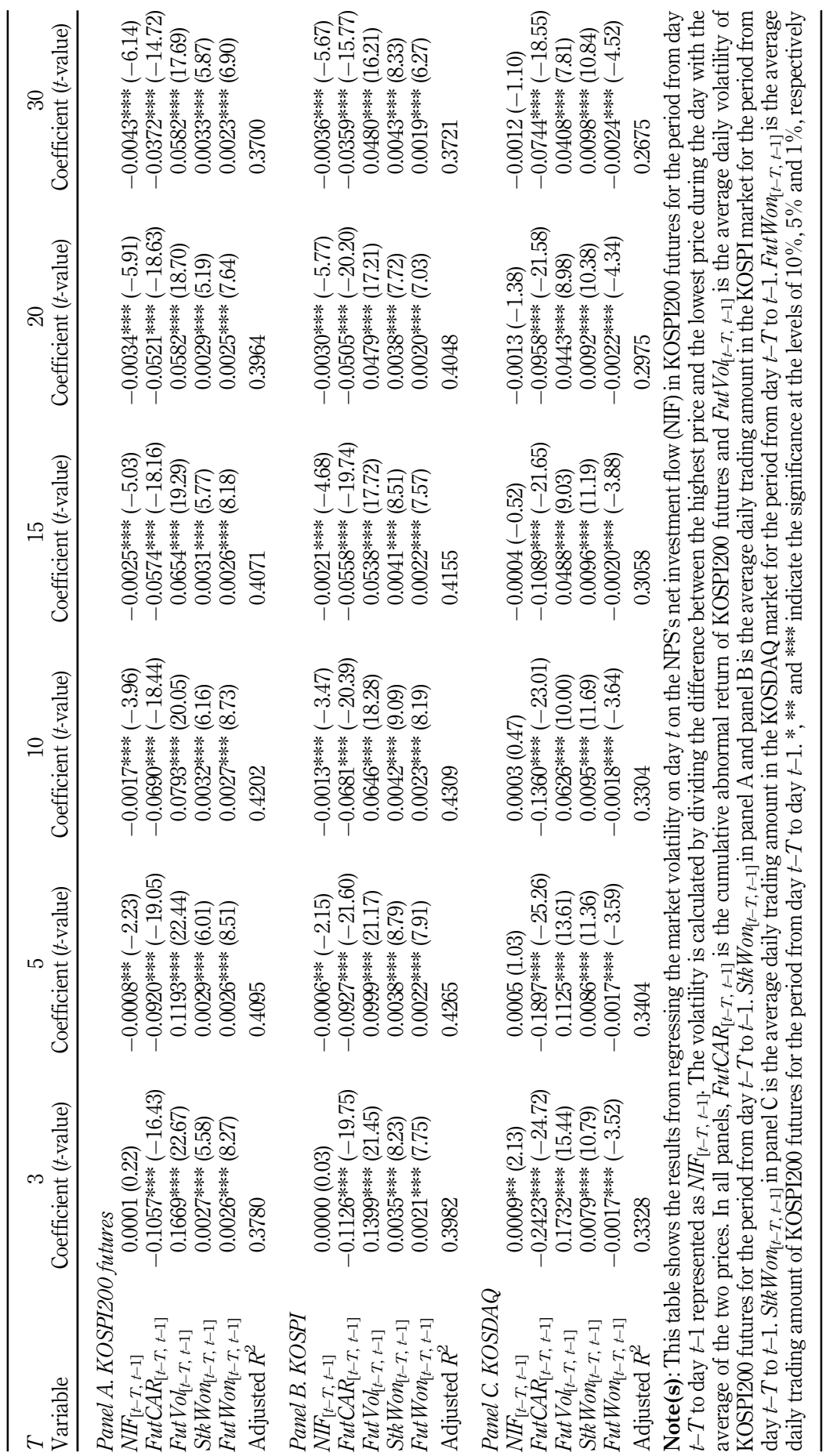

Market impact of futures trading

231

Table 10

The effect of the NPS's NIF on the volatility (II) 
JDQS 29,3

from that of the NPS. It is the limitation of this study that such possibility is not considered in the regression models.

\section{Note}

1. We are very grateful for the anonymous reviewer for this valuable comment.

\section{2}

\section{References}

Amihud, Y. (2002), "Illiquidity and stock returns: cross-section and time-series effects", Journal of Financial Markets, Vol. 5 No. 1, pp. 31-56.

Bae, S.C., Kwon, T. and Park, J. (2004), "Futures trading, spot volatility, and market efficiency: the case of the Korean index futures markets", Journal of Futures Markets, Vol. 24 No. 12, pp. 1195-1228.

Daniel, K., Grinblatt, M., Titman, S. and Wermers, R. (1997), "Measuring mutual fund performance with characteristic-based benchmarks", Journal of Finance, Vol. 52 No. 3, pp. 1035-1058.

Gil, J., Lee, B. and Chung, J. (2015), "The performance and timing ability of the national pension fund", working paper, Korean Finance Association, Conference, Cheonan-si.

Kamesaka, A., Nofsinger, J. and Kawakita, H. (2003), "Investment patterns and performance of investor groups in Japan”, Pacific-Basin Finance Journal, Vol. 11 No. 1, pp. 1-22.

Kang, J. and Ryu, D. (2014), "Which trades move asset prices? An analysis of futures trading data", Emerging Markets Finance and Trade, Vol. 46 No. 1, pp. 7-22.

Kang, J. and Jeong, G. (2018), "Stock return predictability of the Amihud measure in the Korean stock market and trading volume", Korean Journal of Financial Studies, Vol. 47 No. 4, pp. 543-577.

Kang, J., Lee, C. and Lee, S. (2006), "An empirical investigation of the lead-lag relations of returns and volatilities among the KOSPI spot, futures and options markets and their explanations", Journal of Emerging Market Finance, Vol. 5 No. 3, pp. 235-261.

Kho, B., Lee, B., Lee, W. and Hwang, L. (2008), "Does National Pension Service`s trading destabilize Korean stock market?", Korean Journal of Financial Studies, Vol. 37 No. 3, pp. 465-500.

Kim, M. and Woo, M. (2021), "Transaction of the National Pension Service of Korea in the KOSPI 200 futures market", Journal of Derivatives and Quantitative Studies, Vol. 29 No. 2, pp. 156-170.

Ko, K. (2012), "Who wins in the money game? The case of KOSPI 200 futures", Pacific-Basin Finance Journal, Vol. 20 No. 5, pp. 843-856.

Lee, E. (2013), "High frequency trading in the Korean index futures market", Journal of Futures Markets, Vol. 35 No. 1, pp. 31-51.

Min, J.H. and Najand, M. (1999), "Stock index futures: early evidence from Korea", Journal of Futures Markets, Vol. 19 No. 2, pp. 217-232.

Nam, C., Nahm, J. and Lee, J. (2008), "The effects of the Korean national pension fund on stock volatility", Journal of Money and Finance, Vol. 22 No. 1, pp. 83-105.

Ryoo, H. and Smith, G. (2006), "The impact of stock index futures on the Korean stock market", Applied Financial Economics, Vol. 14 No. 4, pp. 243-251.

Ryu, D. (2013), "The information content of trades: an analysis of KOSPI200 index derivatives", Journal of Futures Markets, Vol. 35 No. 3, pp. 201-221.

Schwarz, K. (2012), “Are speculators informed?”, Journal of Futures Markets, Vol. 32 No. 1, pp. 1-23.

Woo, M. and Kim, M. (2015), "Trading pattern of institutional investors in Korean stock market: analysis by institution type", Review of Business and Economics, Vol. 28 No. 3, pp. 1109-1134.

Woo, M. and Kim, J. (2018), "The influence of the Korean National Pension Fund on stock markets", Asian Review of Financial Research, Vol. 31 No. 2, pp. 221-258. 
Woo, M. and Kim, J. (2019), "The effect of National Pension Service trading on KOSDAQ market", Review of Financial Information Studies, Vol. 8 No. 1, pp. 47-73.

Woo, M. and Yang, C. (2019), "The analysis on the investment performance of the national pension fund in Korea", Working Paper, Korean Finance Association, Fall Conference, Seoul.

Market impact of futures trading

Yim, B. (2013), "An empirical study on the effect of the National Pension Fund of Korea on the Korean stock market", Working Paper, Korea Association of Business Education, Fall Conference, Seoul.

\section{Corresponding author}

Meong Ae Kim can be contacted at: meong@kku.ac.kr

For instructions on how to order reprints of this article, please visit our website:

www.emeraldgrouppublishing.com/licensing/reprints.htm

Or contact us for further details: permissions@emeraldinsight.com 